\title{
Summary of improvements to the backfill system at DBS operations
}

\author{
Adam Zajac \& Ryan L. Veenstra \\ Newmont Goldcorp Australia
}

\begin{abstract}
SUMMARY: Newmont Goldcorp Australia's Tanami Operations consists of the Dead Bullock Soak underground mine (DBS) and the Granites Processing Plant. The Backfill Group at DBS has recently introduced a number of improvements to benefit the UG reticulation system. These improvements focused on three areas: reduction of major blockage downtime, continuous monitoring of tight filling operations, and paste plant automation. The first part of the paper will cover the installation of dump/diversion valves throughout the DBS reticulation system. This paper will present why these valves were installed, the design behind determining where they were placed, and several case studies showing how their installation has benefited DBS. The second part of the paper will detail the changes that allow for continuous monitoring of tight filling and present case studies on how this has benefited DBS. The third part of the paper present the results of a trial paste plant automation project which was run in conjunction with NGA's Process Control Group. This section will detail how this automation works and present case studies on how this automation has benefited DBS.
\end{abstract}

Keywords: Continuous Improvement, Valves, Cemented Paste Backfill, Automatic Pilot, Downtime

\section{INTRODUCTION}

Newmont Tanami Operations is in the Northern Territory in the Tanami Desert, Situated $540 \mathrm{~km}$ north-west of Alice Spring on Aboriginal freehold land. The camp is fully equipped 1000 -bed village with the underground mine located $42 \mathrm{kms}$ from the village. Modern mining has been ongoing since 1985 in the Tanami region but the history of gold discovery dates back to 1898 explorer and prospector Allan Davidson, along with his team of four men and nine camels, set off to explore the Tanami Desert. The underground mine is currently $1.4 \mathrm{~km}$ deep with a trucking fleet of 18 trucks.

The DBS cemented paste backfill plant (PP) was commissioned and begun production in March 2012. Until recently, the tailings used at the PP were harvested from decommissioned tailings ponds near the mill, approximately $45 \mathrm{~km}$ away from the DBS. For the first 4 years of production the PP ran these harvested oxide tailings. A dewatering system (cyclone bank and filter belt) was installed at the start of 2018, which utilises the tails stream directly off the mill circuit and allows the blending of the harvested oxide and dewatered tailings. Various blends have been trailed since the dewatering system was brought online with 50/50 Blend currently being used.

DBS is currently expanding and as mining operations start excavating stopes that are both deeper and laterally more distant from the PP, the reticulation network will also need to be expanded. The required placement rate of CPB also increases from approximately $550,000 \mathrm{~m}^{3}$ per year to $775,000 \mathrm{~m}^{3}$ per year over the next few years. This expansion will require improved 
control over the backfill system as well as a reduction in downtime. In order to improve the operating capabilities of the DBS backfill system a series of improvements were implemented. Three of these improvements are summarized in this paper:

1. reduction of major blockage downtime,

2. continuous monitoring of tight filling operations and

3. paste plant automation.

\section{REDUCTION OF MAJOR BLOCKAGE DOWNTIME}

During the early years of backfill production, the PP had minimal down time due to major blockages. A major blockage is classified as a blockage that causes more than a half-a-shift of downtime. This lack of downtime is mainly attributed to new infrastructure and the relatively shallow stopes being filled resulting in short reticulation runs that were easy to unblock. As the mining front moved deeper, clearing blockages became more problematic. During 2016, the PP was down for over two months as a result of multiple major blockages (Figure 1).

This escalating trend of downtime highlighted an area for concern and improvement opportunity. At the start of 2018 NTO started the installation of underground dump and diversion valves.

These valves were chosen because of their ease of use, rapid execution, and improved safety due to reduced manual handling and operator exposure. Dump valves work by decreasing the amount flow resistance while leaving the driving force the same. This allows the CPB to drain through the valve until it reaches equilibrium; flush water is then used to clear the remaining paste upstream of the valve. When valves are used in cascades it allows for rapid clearing of the reticulation system.

Previously, clearing blockages were a slow and labor-intensive process. This would involve independent firing of blast-T caps to release the CPB from the line. If everything went well, it usually took around 1.5 hours to fire a blast-T, drain the paste, flush the line, and re-instate the blast-T. The blasting and manual handling accounted for the majority of this time. The current valves, dependent of the type of valve, take between 15-45 seconds to rotate.

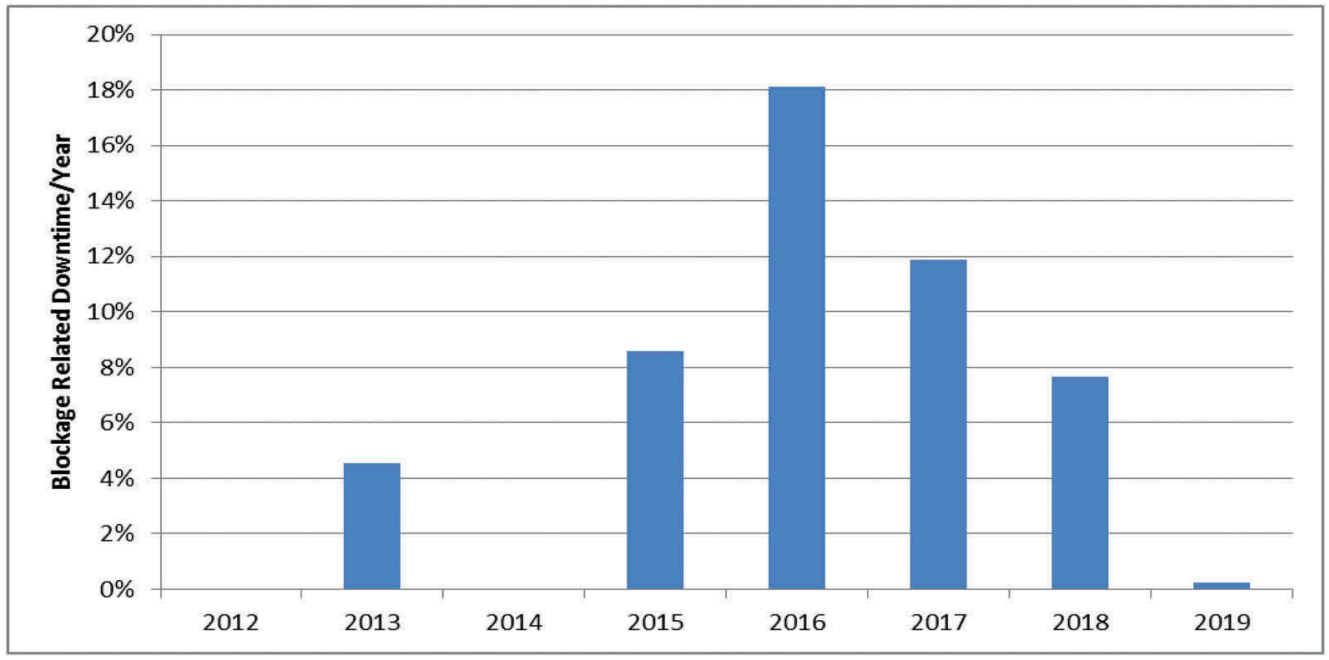

Figure 1. Blockage related downtime per year. 


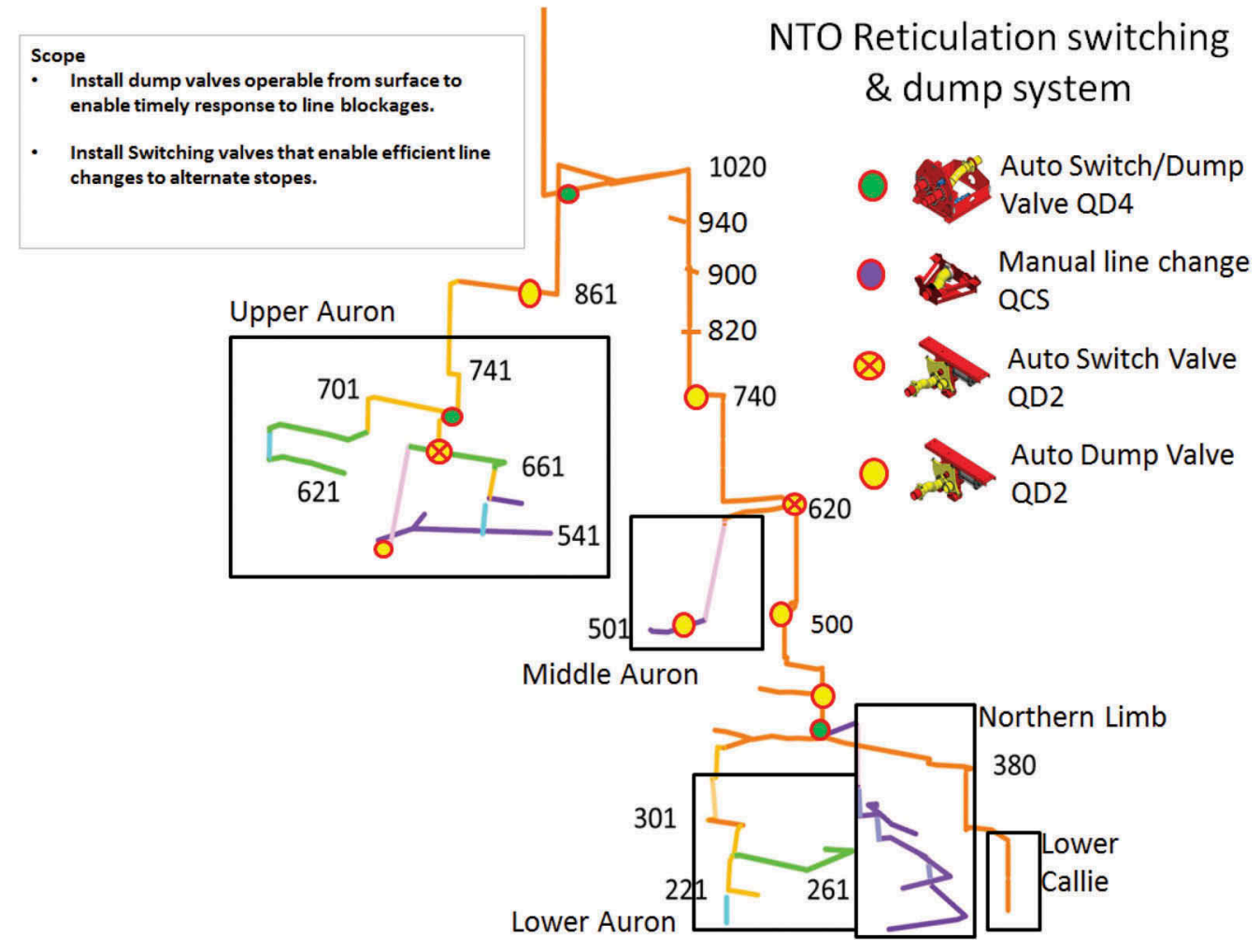

Figure 2. Design schematic of the DBS reticulation system.

Three different types of vales were selected and installed. Automatic hydraulically-driven three-way valves were selected for the main branches to allow flow in three directions (the two branch directions and to dump), automatic pneumatically-driven two-way valves were selected for either dumping or diversion, and manual quick-change valves were selected to allow rapid changes between reticulation lines (i.e. between two stopes). Note that the manual valves are not used to dump the line but only for dry changeovers. An additional benefit to these valves is the reduction of manual handling in order to enact a reticulation line change.

Figure 2 is an example design schematic of the reticulation system, showing the locations of the valves within the system. The schematic also highlights what each valve is being used for (diversion, dumping, diversion/dumping, etc.).

\subsection{Dump valve case study - 136D blockage (no dump valves) versus $127 \mathrm{H}$ blockage (dump valves)}

Figure 3 shows the locations of the $136 \mathrm{D}$ and $127 \mathrm{H}$ stopes. Both stopes were filled using the same line and were at approximately the same location in the mine (the $136 \mathrm{D}$ stope was one level deeper and required a much longer horizontal line to fill).

The 136D stope started filling in October 2017. At around 0700 on the $12^{\text {th }}$ of October the PP recorded a decrease in tailings moisture from approximately $10.5 \%$ to $9 \%$ over a 5 -minute period (Figure 4) and the PP responded accordingly. However, subsequent studies indicated that the installed moisture sensor was uncalibrated and inaccurate, and that the actual decrease seen by the PP was closer to 7\%. This dry material caused a slug of thick CPB to enter the reticulation system. It took approximately 5 minutes to travel through the 1020 level pressure drop measurement loop. This is shown by the rapid rise in friction factor $(\mathrm{kPa} / \mathrm{m})$ 


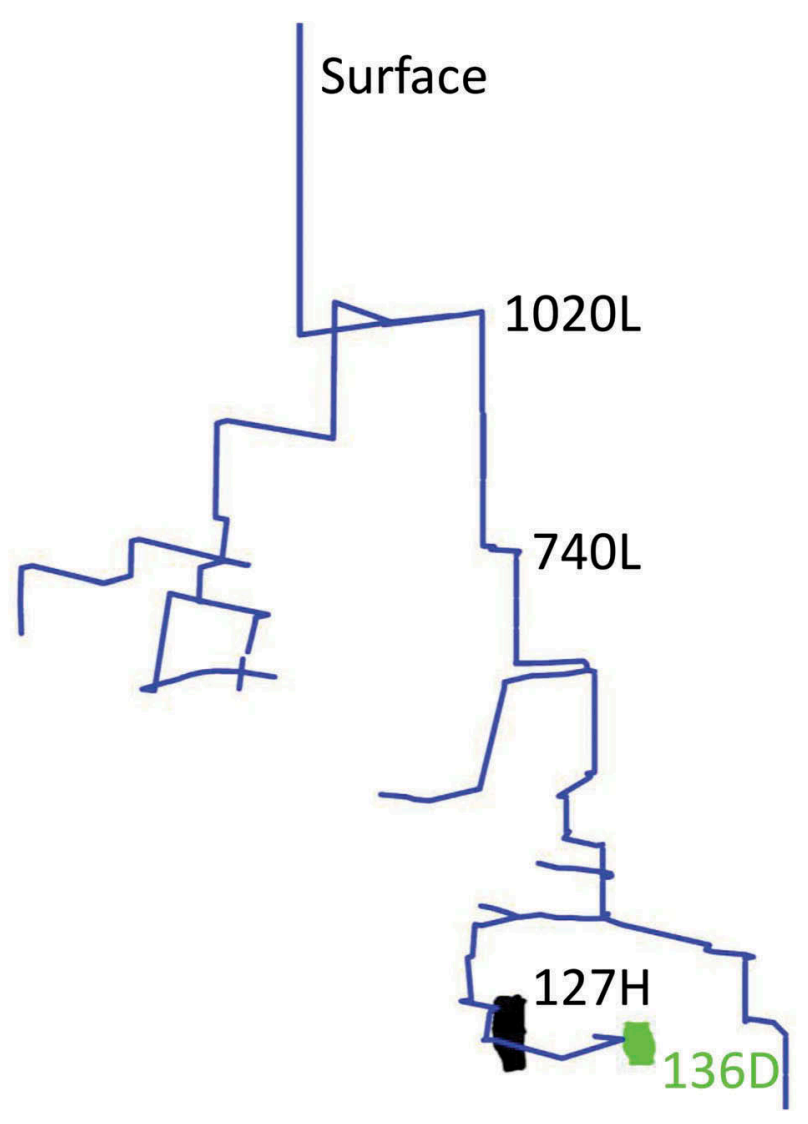

Figure 3. Location of the $136 \mathrm{D}$ and $127 \mathrm{H}$ stopes.

from 5.5 to $11.5 \mathrm{kPa} / \mathrm{m}$ over approximately 10 minutes. During this time the PP operator did respond and dropped the PP's percent solids setpoint but then brought the percent solids up again very quickly. Approximately 30 minutes after the moisture changed the flow decreased to zero. The PP operator was unable to unblock the line using the PP and the underground (UG) operators started UG unblocking operations (firing blast T's). It took 12 hours to clear the reticulation system from surface to the $740 \mathrm{~L}$. After this the UG operators started cracking pipes and a high-pressure washer and diamond drill contractor were brought in clean out the pipes downstream that could not be unblocked. This blockage took 2 months to clean from the $740 \mathrm{~L}$ to the $133 \mathrm{G}$ stope.

The first dump valve was installed at the 1020 Level in January 2018 with the $740 \mathrm{~L}$ valve being installed soon after. These valves were fired for the first time on February 25, 2018.

The causes for this blockage were similar to what caused the 136D blockage. In this case there was a rapid increase in moisture content. However, the PP had not been well tuned to the new moisture analyzer and the PP took too much water away from the mix, causing a slug of thick tailings to enter the reticulation system. This dense paste resulted in a friction factor increase from $\sim 7$ to $\sim 11 \mathrm{kPa} / \mathrm{m}$. The PP operator responded and adjusted their solids, and then shut the plant down and tried to flush the lines using water. The UG operators reached the $1020 \mathrm{~L}$ dump valve first and fired that dump valve manually (the dump valve did not have telemetry with the PP control room yet and needed to be fired manually). This allowed the reticulation system to be cleared of paste to the 1020 level. The paste plant then started filling the reticulation system with water. Once the UG operators reached the $740 \mathrm{~L}$ valve it was also fired manually, clearing the reticulation system to the $740 \mathrm{~L}$. The paste plant was then able to clear the remaining paste through to the stope. 


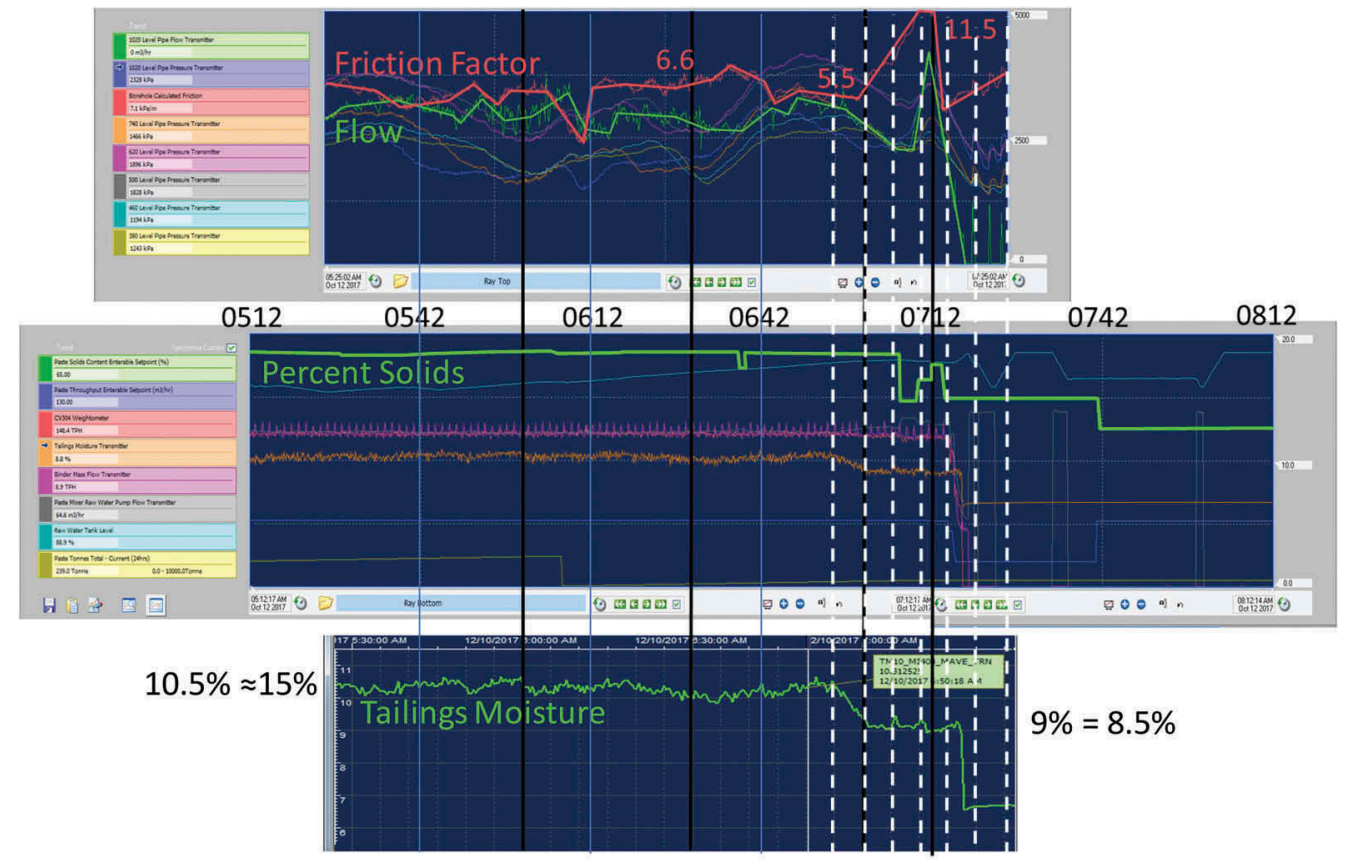

Figure 4. Citect trends from the 136D blockage.

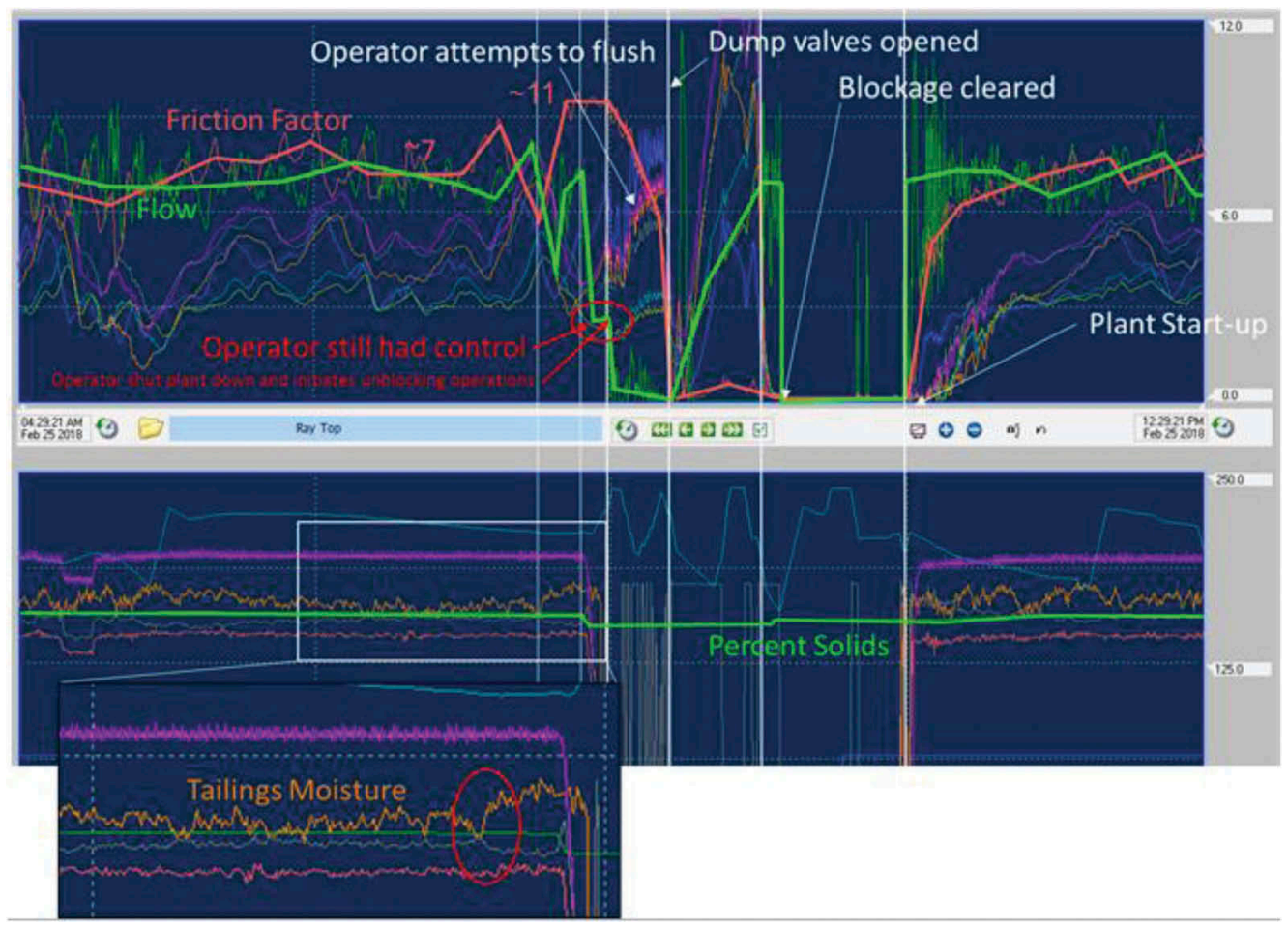

Figure 5. Citect trends from the $127 \mathrm{H}$ blockage. 
The $127 \mathrm{H}$ blockage was cleared within 45 minutes. It required approximately 15 minutes for the underground crew to arrive in position and activate the $1020 \mathrm{~L}$ and $740 \mathrm{~L}$ valve, and another 30 minutes to clear the blockage. Once the blockage was cleared the PP restarted and continued to fill the stope.

This case study highlights how useful the dump valves were in reducing the possible downtime for similar blockage situations. The major advantage to dump valves is the speed at which they can be activated and reset. Additionally, now that telemetry has been established between the UG valves and the PP control room the entire operation can be conducted without requiring UG operators to be present. Dumping points are located in isolated areas where operators are not exposed when the valves are activated.

Since the dump valves were installed there has only been one major blockage, caused by an elbow blowout a level below the last dump valve. The blockage was cleared quickly to the dump valve, but the PP operator was unable to flush the lines once the elbow had been replaced. This example highlights that dump valves are an excellent tool, but they will not clear all blockages.

\section{CONTINUOUS MONITORING OF TIGHT FILLING}

A number of improvement steps were taken to reduce down time during the tight fill process. Tight filling occurs when the last few vertical meters of the stope are being filled which, as this is the case at DBS, generally occurs at the upper access point to the stope. This means that there is a shotcrete wall located at this level which the CPB will be filling against.

Historically, an UG operator was required to act as a spotter; monitoring exclusion areas and visually inspecting the shotcrete wall, and then relaying any relevant information to the PP operator. As the spotter was not available over shift change, normal operating guidelines dictated that the PP shut down once the spotter left and would not start up again until a replacement spotter was in place. This time delay could vary from 4 to 12 hours depending on crew or vehicle availability, and blast fume clearing.

In order to limit this downtime, DBS introduced live feed camera network that along key points of the reticulation system using the PP dedicated fiber network (Figure 6). Fixed cameras were installed on dump/diversion valve locations (allowing visual confirmation that the

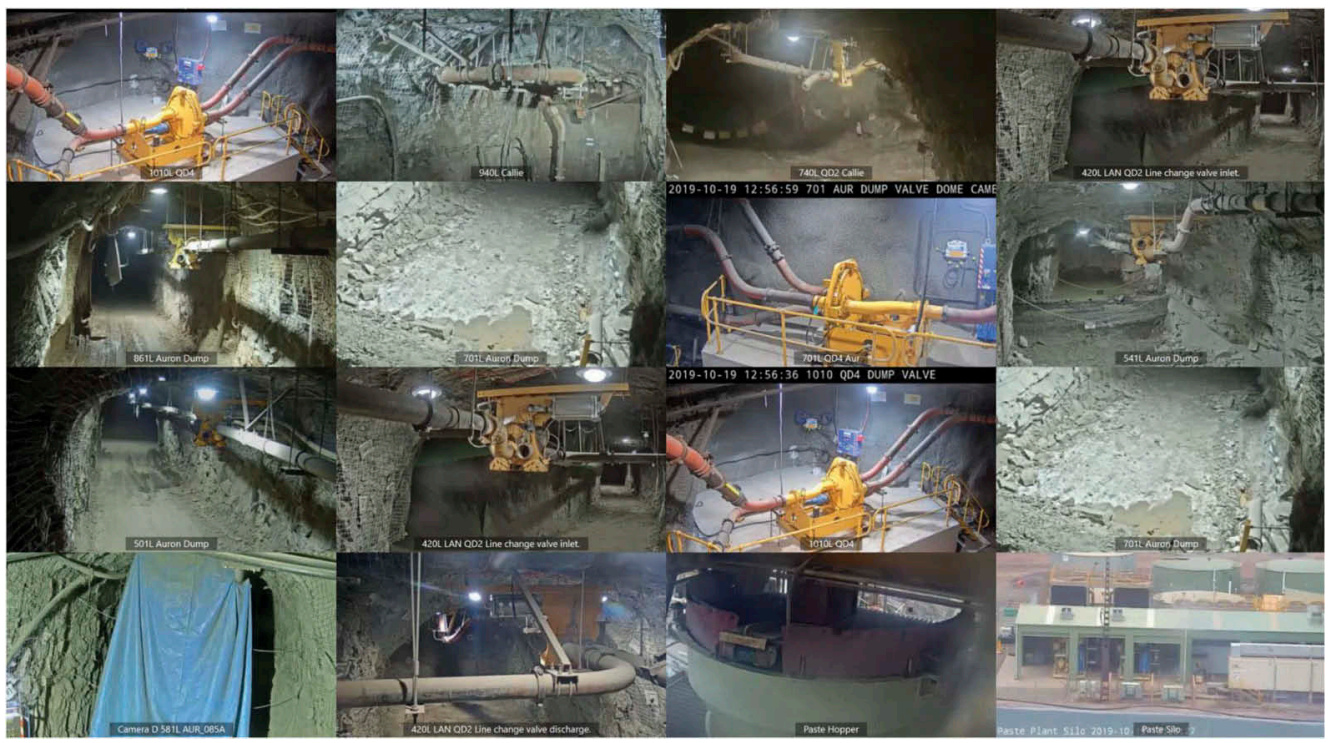

Figure 6. Paste plant operator screen showing the live feed camera network. 
valve had rotated and that the dump zone was clear) as well as problematic areas (areas with high vibration potential etc.). The system also allowed mobile cameras to be placed at filling points. This allowed the PP operator to have a continuous, visible reference that CPB was entering the stope as well as helping eliminate down time over shift change. An additional benefit was that the spotter was no longer required and could be assigned other duties.

However, it was found that the current $25 \mathrm{~mm}$ breather pipes were not sufficient enough to allow the PP to observe if the stope was full. To better aid in the tight fill process the bulkheads were re-designed. An 8-inch (200 mm NB) HDPE drainpipe was installed at the top of the bulkhead. The drain pipe was installed at a decline from the crown of the stope allowing paste to flow into the containment area when tight filling was completed (Figure 7 Figure 8).

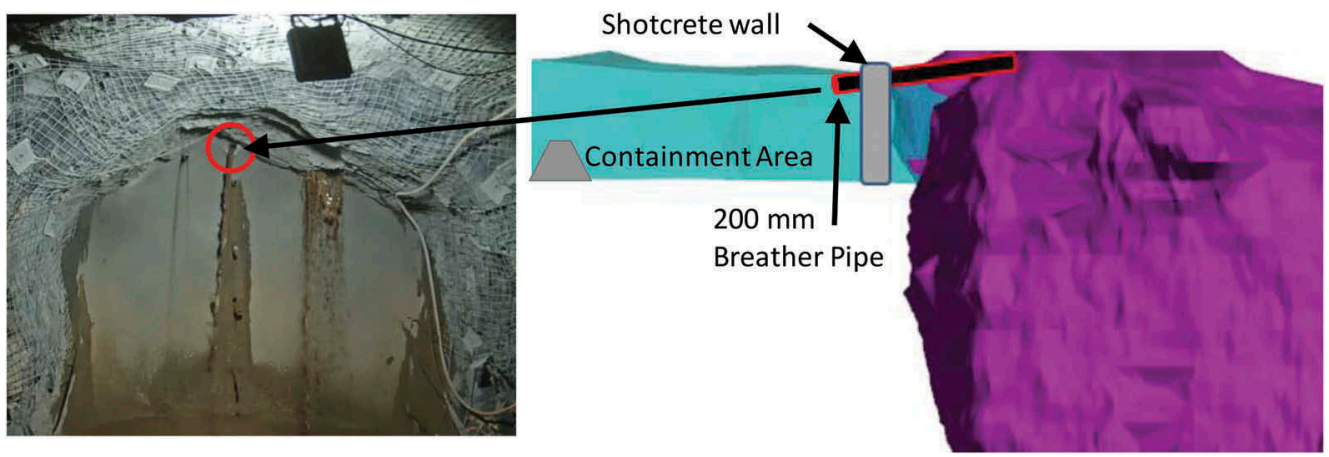

Figure 7. Photograph showing placement of large diameter drainpipe and a schematic showing the ideal placement of the drainpipe through the shotcrete wall.

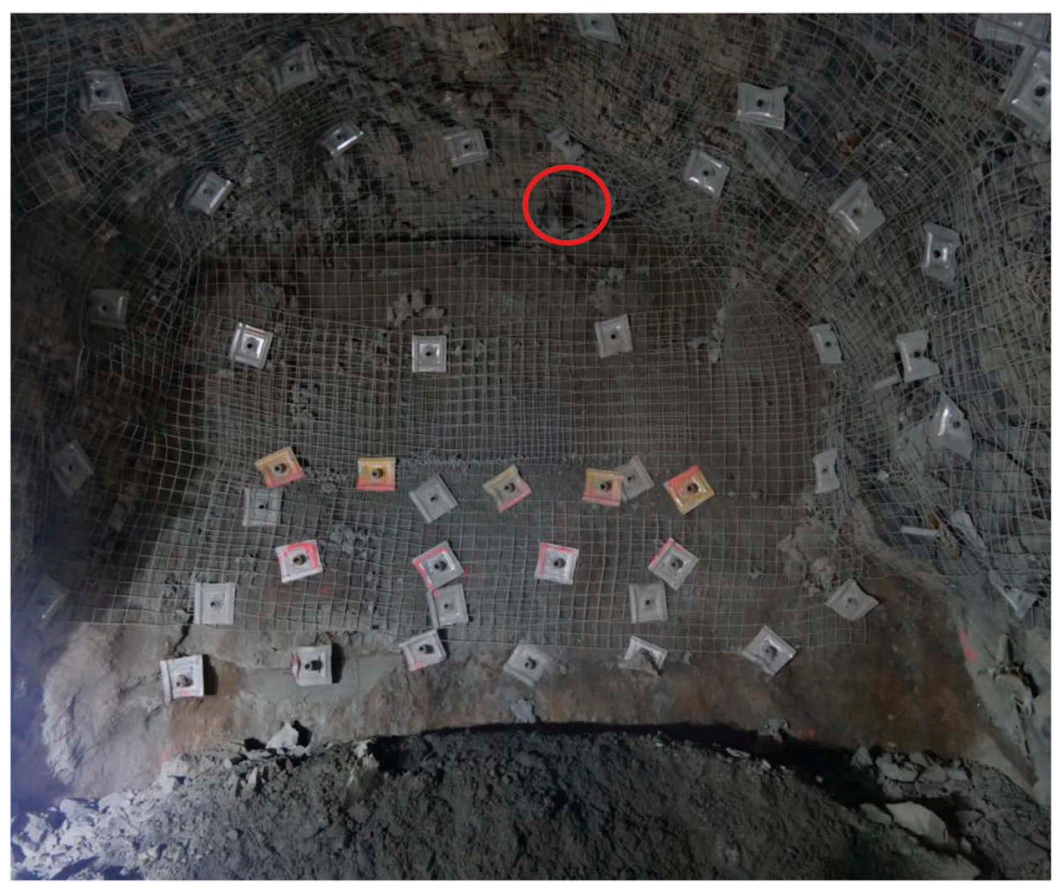

Figure 8. Exposed CPB once wall removed showing 200mm HDPE drain pipe. 
This further removed error when tight filling by allowing either the UG operator via camera or the UG spotter a better reference that the stope was full.

Initially there were concerns that the addition of this large diameter pipe would prevent the tight filling of the stope due to a 'short circuit' between the delivery pipe and the drainpipe. There is evidence that this type of 'short circuit' does occur. However, when both pipes are installed properly there has been no evidence that the large diameter pipe installation prevents the tight filling of the stope. Figure 8 is a photograph showing a CPB exposure from behind a shotcrete wall. The buried end of the large breather pipe is visible, and the stope has been tight filled to the top of the drive. Additionally, this 'short circuit' behavior also protects the shotcrete wall from over-pressurization.

\subsection{Large diameter pipe case study - tight filling with no continuous monitoring of the 145 U stope}

The PP was filling the AUR_145U stope during the early morning and was within $200 \mathrm{~m}^{3}$ of starting the normal tight filling procedure as per the CMS run sheet. This run sheet determines the height of the CPB level within the stope based on dead reckoning using the amount of $\mathrm{CPB}$ volume placed versus the total volume of the stope. The CPB containment area bunds were in place. A large diameter drainpipe had been installed into the shotcrete wall. However, no camera had been installed as the fiber network could not be expanded in time.

DBS requires a reticulation check (visually inspect the shotcrete wall, containment area, and the reticulation system etc.) every 6 hours. However, no line checks had been completed on night shift. The CPB level was higher in the stope than what was determined on the CMS run sheet and, subsequently, CPB started filling the containment area at $\sim 04 \mathrm{~h} 45$. This was not rectified until the first dayshift lined checks approximately 5 hours later. A total of $510 \mathrm{~m}^{3}$ were overfilled in total: $\sim 440 \mathrm{~m}^{3}$ within the containment area and $\sim 50 \mathrm{~m}^{3}$ was spilled over the exclusion bund. Figure 9 shows a level plan with the approximate locations of the bunds and the overflow as well as two pictures from the drive after the CPB was removed.

This case study highlights importance of the entire system being in place. The large diameter drainpipe worked as it was supposed to and gave a visual reference that the stope was full. The unfortunate part was that nobody was watching.

Additionally, the installation of the drainpipe protected the shotcrete wall from overpressurization to the point that the PP operators did not observe any changes in the pipeline pressures. The shotcrete wall showed no signs of stress-related damage when inspected. This single control eliminated the potential for a bulkhead failure and a sudden inrush or a pipe blockage.

\section{AUTOMATIC PASTE DENSITY SETPOINT CONTROL}

Another improvement introduced into the DBS backfill system was a PP control system referred to as the 'Automatic Paste Density Setpoint Controller' or OTTO. This controller is not being developed to replace the operator but to allow the operator an 'autopilot' freeing the operator for other PP related tasks. The controller was developed between DBS site personel and Newmont Goldcorp Australia's Process Control Group.

OTTO uses the 1020L pressure value as input to a standard PID (proportional integral derivative) controller that manipulates the paste mixer feed density setpoint. This controller manipulates the same setpoint edited by the control room operator via the Citect popup. The PID controller makes small adjustments based on the rate of change and comparing the actual value of the $1020 \mathrm{~L}$ pressure value to its setpoint (which varies given the configuration of the reticulation system). The paste density setpoint is only allowed to vary within the following operator-specified limits. Ideally, OTTO would first aim to control a 1020L flow in order to then control the 1020L pressure. However, issues with inconsistent tailings feed often result in a highly unstable $1020 \mathrm{~L}$ flow, and therefore not possible to control flow automatically. Instead, to further emulate typical control room operator actions some additions applied to the basic pressure controller described below: 

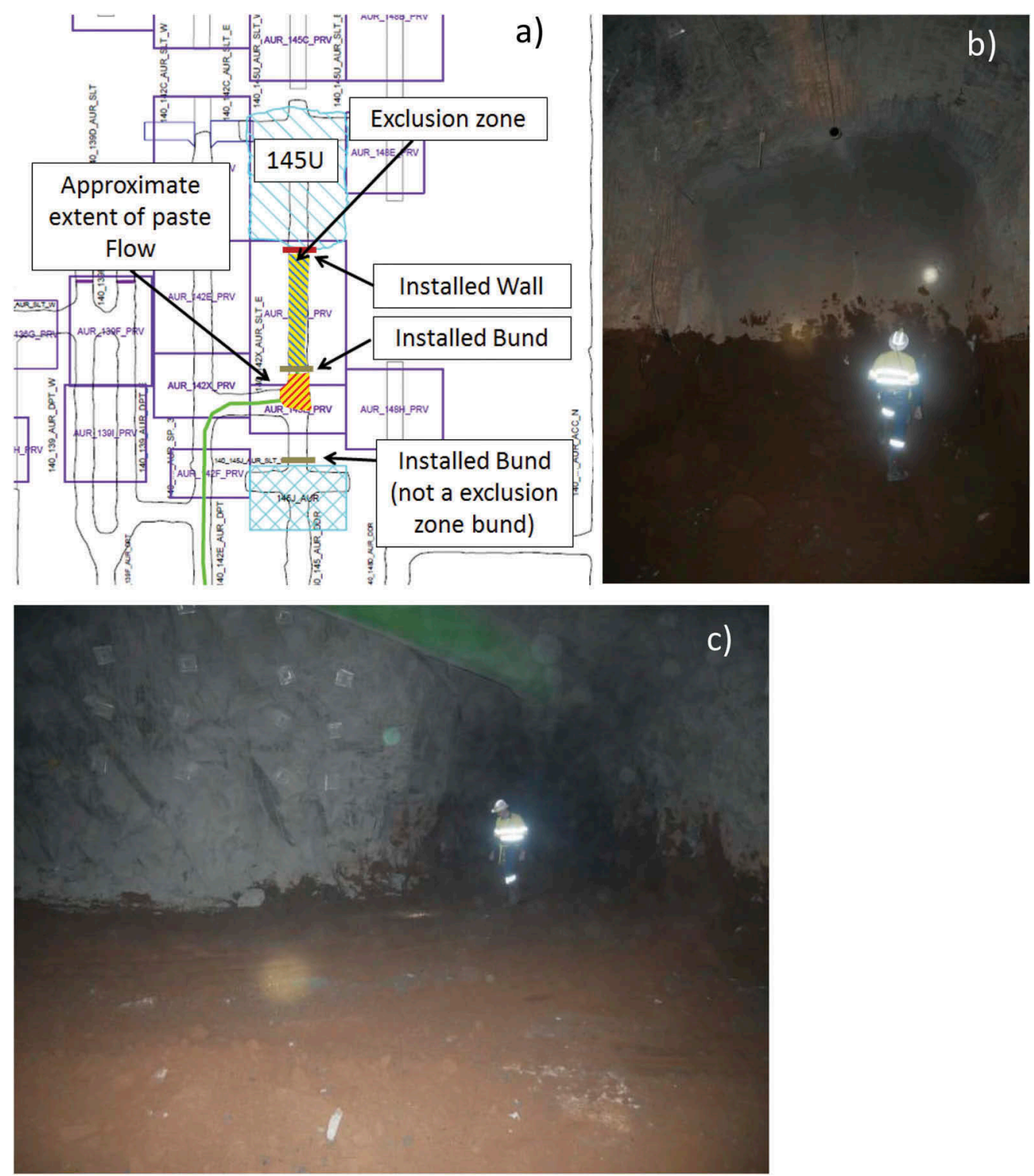

Figure 9. Paste 145U overfill showing a) level plan with approximation of location of bunds, b) paste staining at the shotcrete wall location, and c) paste staining along the drive.

- If $1020 \mathrm{~L}$ pressure increasing and/or 1020L pressure above setpoint -> paste mixer feed density reduced

- If $1020 \mathrm{~L}$ pressure decreasing and/or 1020L pressure below setpoint -> paste mixer feed density increased

While the controller is primarily a pressure controller, 1020L flow can optionally be included as a feed-forward input to the pressure controller. This will immediately make small adjustments to the paste density setpoint (when enabled) based on the changes in $1020 \mathrm{~L}$ flow as per below:

- If $1020 \mathrm{~L}$ flow increases, slightly increase paste mixer feed density.

- If 1020L flow decreases, slightly decrease paste mixer feed density. 


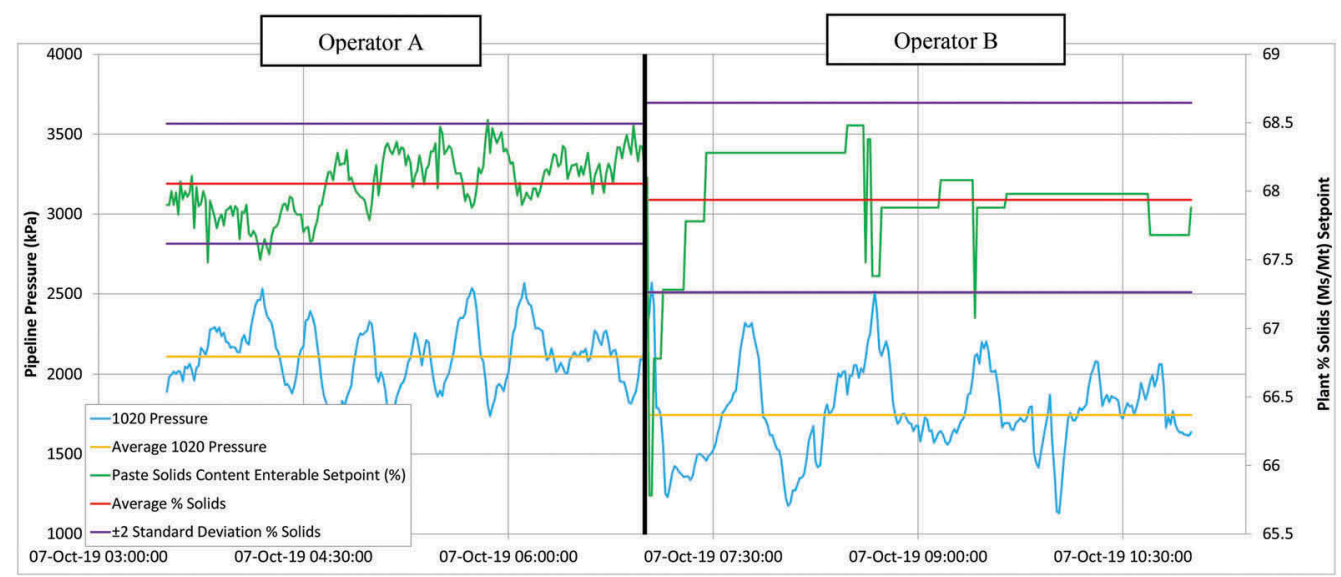

Figure 10. Citect trends showing the difference between the performance of OTTO and a PP operator.

The assumption is that a change in flow will result in a subsequent change in pressure.

Finally, as an option, the borehole vacuum pressure can be included as a feed-forward input to the pressure controller. This emulates a typical operator response to a loss of borehole pressure. This control is more aggressive than the 2 above, as it must assume the loss of flow and vacuum is real, and therefore allows for radical changes of the paste density setpoint

In practice the PP operators generally run OTTO only using the basic $1020 \mathrm{~L}$ control. Occasionally the operators will run with the flow control if the tailings feed is consistent. An upgraded flow meter has recently been installed on the reticulation system and this has improved the flow measurement. None of the operators utilize the borehole vacuum pressure option.

Further improvements to OTTO are planned. These primarily deal with utilizing the lag time between the mixer and the flow and pressure measurements at the $1020 \mathrm{~L}$ to optimize OTTO's performance. However, this has not been fine-tuned as the trial of the basic system is ongoing.

Figure 10 shows Citect trends for the percent solids setpoint and the 1020L pressure over a 24-hour period. During this time there where two different operators running the plant: Operator A was running OTTO, while Operator B controlled the PP with manual density changes. OTTO and Operator B maintained average percent solids setpoints of $68.1 \%$ and $67.9 \%$ respectively. However, the average $1020 \mathrm{~L}$ pressures, over this time, were $2111 \mathrm{kPa}$ for OTTO and $1756 \mathrm{kPa}$ for Operator B. OTTO was set to $2100 \mathrm{kPa}$.

Relatively speaking the percent solids averages are similar. However, the percent solids variability between the two operators is large and is highlighted by the purple lines denoting \pm 2 standard deviation of the percent solids. The tighter percent solids control allowed OTTO to maintain a line pressure that was approximately $350 \mathrm{kPa}$ higher over the time period monitored.

\section{CONCLUSIONS}

The expansion of the DBS mine requires the subsequent expansion of the reticulation system as well as an increase in the CPB placement rate and requires improved control over the backfill system as well as a reduction in downtime. Multiple improvements have been initiated at DBS, with three of these improvements being summarized in this paper.

The installation of dump/diversion valves have decreased the occurrence of major blockage downtime from over $10 \%$ in 2016 and 2017 to less than 1\% in 2019. It has also reduced reticulation change downtime and the amount of manual handling required to enact these changes. 
This control system was designed and installed to improve productivity, but the safety impact by reducing manual handling of pipes when blockages occur, almost outweighs the operational improvements.

The continuous monitoring improvement has decreased downtime due to spotter constraints during tight filling operations by allowing the PP operator to visual observe the shotcrete wall in real-time. This improvement also allows the PP operator to have a visual reference to how the reticulation system is performing at key areas as well as allowing the PP operator to observe $\mathrm{CPB}$ entering the stope. Part of this was the installation of large diameter drainage pipes that provides a better visual reference that the stope is filled. An additional benefit of this larger diameter pipe is that it prevents the shotcrete wall from being overpressurized but still allows the stope to be tight filled.

The last improvement was the introduction of OTTO or the PP 'autopilot'. In OTTO's basic form it modifies the percent solids setpoint in order to maintain a set pressure at the $1020 \mathrm{~L}$ pressure sensor. It does this by observing the rate of change and the value of this pressure sensor. OTTO is still being trialled, but initial results are encouraging. Additional modifications and improvements are ongoing.

\section{ACKNOWLEDGEMENTS}

The Authors would like to acknowledge the Newmont Goldcorp Australia Process Control Group, particularly Craig Sempf and Aidan Hill, for their ongoing help and support with OTTO. The Authors also acknowledge the Newmont Goldcorp Tanami Management Team for their support in the writing of this paper. 